
Informations

une revue Gallia

Centre | 1998

\title{
Saint-Jean-de-Braye - Clos-de-Roche
}

$\mathrm{n}^{\circ} 064393$

Jocelyne Vilpoux et Laurent Fournier

\section{(2) OpenEdition}

Édition électronique

URL : http://journals.openedition.org/adlfi/14350

ISSN : 2114-0502

Éditeur

Ministère de la culture

Référence électronique

Jocelyne Vilpoux et Laurent Fournier, « Saint-Jean-de-Braye - Clos-de-Roche », ADLFI. Archéologie de la France - Informations [En ligne], Centre, mis en ligne le 20 mars 2015, consulté le 24 avril 2019. URL http://journals.openedition.org/adlfi/14350

Ce document a été généré automatiquement le 24 avril 2019

(C) Ministère de la Culture et de la Communication, CNRS 


\title{
Saint-Jean-de-Braye - Clos-de-Roche
} $n^{\circ} 064393$

\author{
Jocelyne Vilpoux et Laurent Fournier
}

Lien Atlas (MCC) :

http://atlas.patrimoines.culture.fr/atlas/trunk/index.php?

ap_theme=DOM_2.01.02\&ap_bbox=1.930;47.900;2.009;47.943

1 Le projet de construction d'un lotissement sur une superficie de près de quinze hectares est à l'origine de l'opération archéologique.

2 C'est sur la partie ouverte en 1997 où la densité des vestiges était la plus forte, soit un hectare et demi, qu'a été conduite l'opération.

3 Révélé lors des évaluations préalables, le site présente une exploitation rurale des Haut et Bas-Empire et une nécropole mérovingienne.

4 Situés sous un couvert de terre végétale d'une cinquantaine de centimètres, les vestiges sont apparus fortement arasés. Non stratifié, nous privant d'une interprétation fonctionnelle de nombreuses structures et d'un calage chronologique précis, le site offre cependant un ensemble cohérent et spatialement compréhensible qui évolue sur trois grandes périodes chronologiques du milieu du $\mathrm{I}^{\mathrm{er}} \mathrm{s}$. à la fin du VII $\mathrm{e}$ s. apr. J.-C.

5 Pour la période du Haut-Empire qui voit l'implantation d'une villa vers le milieu du $\mathrm{i}^{\mathrm{er}}$ s. apr. J.-C., l'ensemble agraire est assez bien identifié malgré le recouvrement par les phases d'occupation postérieures.

6 Cette exploitation prend place sur un site déjà fréquenté durant la période protohistorique dont témoigne une fosse renfermant du matériel céramique daté du Hallstatt moyen et quelques ensembles mobiliers épars.

7 La villa est installée sur le point haut du site en extrémité de plateau, et domine la vallée de la Bionne, affluent de la Loire. La séparation entre l'espace réservé à la villa et le domaine agricole est matérialisé par des fossés à la fonction drainante. 


\section{Le Haut-Empire ( $\mathrm{I}^{\mathrm{er}}-\mathrm{III} \mathrm{e}$ s.)}

8 Le premier bâtiment est une construction modeste dont l'élévation de terre et de bois est fondée sur un solin de petites pierres calcaires. Une fosse rectangulaire découverte dans l'espace circonscrit par ce bâtiment a livré un important matériel céramique qui nous permet de dater son abandon dans la première moitié du $\mathrm{I}^{\mathrm{er}} \mathrm{s}$. apr. J.-C. Il est possible que cette première installation ait servi de "base » aux hommes affectés au défrichement et à l'assainissement du site (l'important réseau de drainage mis au jour daterait de cette période).

Par la suite, les constructions se multiplient.

10 Elles se répartissent en trois corps de bâtiment, le premier, situé à l'ouest, abrite les parties résidentielles (pars urbana), le second, découvert à l'est, semble plutôt dévolu à des activités de stockage, le troisième abrite des activités à caractère artisanal (fours de métallurgie), ils constituent la pars rustica. Les élévations de ces bâtiments sont assises sur un blocage constitué de moellons grossièrement équarris, noyés dans un mortier maigre.

11 L'activité de " récupération " particulièrement importante sur le site ne nous a souvent permis d'observer le mode de construction de ces premiers bâtiments qu'au fond des tranchées de fondation.

12 La pars urbana: dans la partie résidentielle (bâtiment 2), chauffée grâce à un système d'hypocauste, les murs étaient ornés d'enduits peints à motifs géométriques et le sol couvert par une mosaïque, dont quelques éléments (tesselles et fragments d'enduits) ont été mis au jour dans les remblais des tranchées de récupération des murs.

La pars rustica : les aménagements à l'intérieur du deuxième bâtiment dédié au stockage des récoltes (cave, citerne et peut-être cuve de pressoir qui pourrait indiquer l'existence d'une activité viticole) sont construits en petit appareil (bâtiment 3).

Le troisième bâtiment, situé au sud de la pars urbana, a livré les restes de deux foyers de forge (bâtiment 4). La présence de ces deux fours relève sans doute plus d'une intégration à une économie de caractère domanial et autarcique (fabrication ou réparation d'ustensiles et d'outils nécessaires à l'activité agricole) qu'à une production d'objets destinés aux marchés.

15 L'ensemble de ces bâtiments s'organise autour d'un espace de cour intérieure et est ceinturé par un réseau de fossés drainants. La villa est desservie par un chemin axé nordsud, qui débouche le long du bâtiment 4.

16 Une mare, dont le fond est partiellement aménagé à l'aide de fragments de tuiles et de moellons calcaires, se trouve au sud-est de ces constructions. Elle recueille notamment les eaux du système drainant des fondations du bâtiment.

17 Le bâti évolue tout au long de ces trois siècles. Au cours du II ${ }^{\mathrm{e}} \mathrm{s}$. des ajouts sont accolés à des bâtiments existants et des modifications interviennent dans les aménagements liés au drainage. À l'emplacement du bâtiment du $\mathrm{I}^{\mathrm{er}} \mathrm{s}$., un lieu de culte païen est implanté. Une fosse, abritée par une construction légère sur poteaux, est creusée. Un vase à fond perdu y a été découvert. Ce récipient, dont seul le col dépassait du niveau du sol composé de tuiles (tegulae), était rempli de restes d'offrandes carbonisées. L'abandon de cette fosse rituelle est daté de la seconde moitié du $\mathrm{III}^{\mathrm{e}} \mathrm{s}$. 
18 À la fin du $\mathrm{III}^{\mathrm{e}} \mathrm{s}$., l'ensemble des constructions est abandonné et les matériaux récupérés afin d'être réutilisés. La mare est comblée.

\section{Le Bas-Empire (IV $\mathrm{s}$.}

La phase d'abandon semble être de courte durée. Les constructions de cette phase font plus largement appel au bois et à la terre. Le bâtiment principal est réoccupé et un grand nombre de constructions sont réalisées attestant de la vocation agro-pastorale du nouvel établissement. Mais l'embellie semble de courte durée et, dès la seconde moitié du IV $\mathrm{s}$., le site est à nouveau déserté pendant deux siècles.

\section{La période du haut Moyen Âge}

20 Il faut attendre la période mérovingienne pour que le site soit réoccupé. Un petit habitat et une nécropole s'installent de part et d'autre d'un chemin bordé par deux fossés, qui répond à une orientation est-ouest. L'une des sépultures a livré les restes d'une femme ensevelie avec ses bijoux dont une plaque-boucle en fer rehaussée de motifs damasquinés de cuivre et d'argent. Les derniers témoins de l'occupation du site (bâtiments sur poteaux, fossés parcellaires) marquent l'abandon définitif du site à la fin du viI $\mathrm{s}$.

21 L'étude des vestiges de Saint-Jean-de-Braye nous permet de replacer ce site important dans son cadre local et régional. Les études conjointes qui peuvent être menées aussi bien au niveau de l'évolution de l'habitat (intégration dans l'espace, matériaux de construction employés...), qu'au niveau de la population (étude anthropologique qui permettrait peutêtre de vérifier la validité de l'hypothèse de l'installation d'une population exogène au cours $\mathrm{du} \mathrm{VII}^{\mathrm{e}} \mathrm{s}$.), doivent nous apporter une masse de renseignements qui enrichiront notre connaissance de ces périodes charnières entre l'Antiquité et le haut Moyen Âge.

\section{INDEX}

Index géographique : Centre, Loiret (45), Saint-Jean-de-Braye

Index chronologique : Gallo-romain, haut Moyen Âge

Mots-clés : villa, nécropole, céramique, pars rustica, pars urbana, habitat, sépulture, bijoux operation Sauvetage programmé (SP) 